\title{
NARRATIVAS DE MULHERES SOBRE O PASSADO DA AMÉRICA: DA EXCLUSÃO HISTÓRICA AO PROTAGONISMO FICCIONAL
}

\author{
Amanda Maria Elsner Matheus ${ }^{1}$ \\ Gilmei Francisco Fleck ${ }^{2}$ \\ Tatiane Cristina Becher ${ }^{3}$
}

\begin{abstract}
Resumo: A escrita da história, por séculos, foi reduto masculino, ocupado por privilegiados homens que tiveram acesso à instrução. Tais homens eram contratados pelo poder para registrar os eventos de cada reinado. Assim se deu na América, cujo passado foi escrito pelos conquistadores a serviço dos monarcas a quem serviam como cronistas. Essa configuração unilateral da história da América tem levado muitos romancistas americanos a revisitarem o passado e a reescreverem episódios marcantes de cada nação sob diferentes perspectivas. A releitura da história pela ficção é ainda mais significativa quando feita por uma das parcelas excluídas dos discursos oficiais, como é o caso das mulheres. Neste texto, verificamos como a escrita híbrida contemporânea de autoria feminina tem se ocupado do passado americano, conferindo-lhe inusitadas visões, múltiplas perspectivas e inquietantes possibilidades de leituras. Palavras-chave: Ressignificações do passado. Narrativas de autoria feminina. Romance histórico. Personagens femininas. "Descobrimento", conquista e colonização da América.
\end{abstract}

\section{WOMEN'S NARRATIVES ABOUT THE AMERICAN PAST: FROM HISTORICAL EXCLUSION TO FICTIONAL PROTAGONISM}

Abstract: The writing of history, for centuries, was a male stronghold, occupied by privileged men who had access to education. These men were hired by the rulers to register the events of each reign. This is what happened in America, whose past was written by the conquerors in the service of the monarchs whom they served as chroniclers. This one-sided configuration of American history has led many American novelists to revisit the past and to rewrite striking episodes of each from different perspectives. This rereading of history by fiction is even more effective when done by one of the groups excluded from official speeches, such as the case of

\footnotetext{
${ }^{1}$ Mestre em Letras, na área de Linguagem Literária e Interfaces Sociais: Estudos Comparados pela Universidade Estadual do Oeste do Paraná (2021). Pós-Graduada em História e Cultura Brasileira e Africana, Gestão Escolar e Educação Especial Inclusiva, pela Faculdade de Educação e Tecnologia da Região Missioneira - FETREMIS. Graduada em Letras Português/Espanhol pela Universidade Estadual do Oeste do Paraná (2009). Atualmente é professora concursada do estado do Paraná e ministra aulas de Língua Portuguesa e Espanhola no Colégio Estadual Princesa Isabel.

2 Possui Pós-doutorado (2015) em Literatura Comparada e Tradução, pela Universidade de Vigo-UVigoEspanha, com Bolsa da CAPES; Mestrado (2005) e Doutorado (2008) em Letras, pela Universidade Estadual Paulista - UNESP/ Assis. Atualmente, é Professor de Literaturas Hispânicas e Cultura Hispânica na graduação em Letras da Unioeste, campus de Cascavel-PR. Atua também no Programa de PósGraduação acadêmico em Letras da instituição, na área de Literatura Comparada e Tradução, e no Programa de Pós-Graduação "Mestrado Profissional-Profletras", na área de Literatura Infantil e Juvenil.

${ }^{3}$ Doutoranda do Programa de Pós-Graduação em Letras da Universidade Estadual do Oeste do Paraná (Unioeste). Bolsista da CAPES/CNPq. Integrante do grupo de pesquisa "Ressignificações do passado na América: processos de leitura, escrita e tradução de gêneros híbridos de história e fícção - vias para a descolonização", coordenado pelo professor Gilmei Francisco Fleck. Mestre em Letras (Unioeste). Licenciada em Letras - Português/Inglês e suas respectivas literaturas (Unioeste). Bacharel em Administração (Unioeste).
}

Revista Escritas do Tempo - v. 3, n. 8, mai-ago/2021 - p. 244-262 
women. In this text, we verify how contemporary hybrid texts written by women have been concerned with the American past, giving it unusual views, multiple possibilities, and thoughtprovoking possibilities of reading.

Keywords: Resignifications of the past. Narratives by female authors. Historical novel. Female characters. "Discovery", conquest and colonization of America.

\section{NARRATIVAS DE MUJERES SOBRE EL PASADO DE AMÉRICA: DE LA EXCLUSIÓN HISTÓRICA AL PROTAGONISMO FICCIONAL}

Resumen: La escrita de la historia, durante siglos, fue reducto masculino, ocupado por privilegiados hombres que tuvieron acceso a la instrucción. Estos eran contratados por el poder para registrar los eventos de cada reinado. Así se dio en América, cuyo pasado fue escrito por los conquistadores al servicio de los monarcas a quienes sirvieron como cronistas. Tal configuración unilateral de la historia de América ha llevado muchos novelistas americanos a revisitar el pasado e a reescribir episodios notables de cada nación bajo diferentes perspectivas. Esa relectura de la historia por la ficción es aún más significativa cuando hecha por una de las partes excluidas de los discursos oficiales, como es el caso de las mujeres. En este texto, verificamos como la escritura híbrida contemporánea de autoría femenina se ha ocupado del pasado americano, otorgándole inusitadas visiones, múltiples perspectivas e inquietantes posibilidades de lecturas.

Palabras clave: Resignificaciones del pasado. Narrativas de autoría femenina. Novela histórica. Personajes femeninos. "Descubrimiento", conquista y colonización de América.

A história da América constitui, segundo os compêndios da historiografia, uma era de grandes heróis e feitos admiráveis. Fatos que se encontram registrados nos anais das diferentes fases da história do "descobrimento", conquista, colonização e, mais tarde, das independências no continente, comprovam essa afirmativa revelada por meio de narrativas que se encontram entre o real e o fantástico. Figuras femininas relevantes nesses processos ficam à margem dos registros feitos, exclusivamente, por uma pequena parcela de homens letrados, muitas vezes, a serviço dos monarcas das metrópoles colonizadoras. Em suas escritas, são mencionadas apenas aquelas mulheres cujas ações são realmente imprescindíveis aos registros oficiais, como, por exemplo, a atuação da rainha Isabel, da Espanha, já que foi ela quem concedeu a Colombo os meios necessários para realizar a sua inusitada viagem.

A escrita híbrida contemporânea de autoria feminina, ou seja, o romance histórico escrito por mulheres sobre mulheres, busca aclarar e retificar as omissões históricas em relação à sua atuação ao longo dos tempos. Ciplijauskaité, autora de La novela femenina contemporánea (1970-1985): hacia una tipología de la narración en primera persona (1994), assinala que os romances históricos femininos centram-se na tentativa de circunscrever a mulher na história, porém, à revelia das representações tradicionais, 
voltados para as novas tendências historiográficas, que preferem não se fixar nos grandes acontecimentos e nas figuras consagradas.

Em Mujer e identidad en la narrativa histórica femenina (2006), Navarro Salazar une o conceito de romance histórico feminino com o fenômeno do feminismo, afirmando que um dos propósitos fundamentais das mulheres está em formar sua própria identidade, de maneira que, tanto as autoras como as protagonistas femininas "[ [... podem encontrar suas genealogias em vozes de mulheres do passado"4 (NAVARRO SALAZAR, 2006, p. 218 - tradução nossa). Dessa forma, a autora destaca que o problema de construir a identidade individual e coletiva por meio da revisão da história é, provavelmente, o aspecto primordial no novo conceito de romance histórico feminino.

Para Schmidt (2013), refletir historicamente a constituição das histórias da literatura brasileira significa pensar a partir de questões relacionadas ao binarismo de gênero, que atua como um operador ideológico que legitima sua codificação na tradição literária através do gênero da autoria, de certas linguagens e estruturas textuais utilizadas para ratificar poderes hegemônicos nos campos sociais, culturais e políticos. Segundo a autora, "[n]ão há como negar o fato de que a cultura literária masculina, a partir da qual se construiu modelos de história literária que ainda têm vigência entre nós, segue a linha de uma história política dominada quase que exclusivamente por homens, daí a razão pela qual pode ser qualificada como uma história patriarcal” (SCHMIDT, 2013, n. p.).

Buscamos, portanto, por meio do presente artigo, demonstrar como a escrita híbrida contemporânea de autoria feminina tem se ocupado do passado americano, conferindo-lhe inusitadas visões, múltiplas perspectivas e inquietantes possibilidades de leituras, de modo a evidenciar, por meio da ficção, a atuação de figuras históricas femininas marginalizadas pela história hegemônica, alterando, assim, sua posição secundária.

Entre essas esquecidas personagens estão a esposa portuguesa de Cristóvão Colombo - Felipa Moniz Perestrello - e a jovem cordobesa Beatriz Enríquez de Harana, sua fiel companheira em toda a jornada em busca do apoio dos reis católicos da Espanha. A primeira delas, a portuguesa Felipa Moniz Perestrello, foi uma mulher que, sem dúvida, ofereceu-lhe apoio incondicional para pôr em prática o seu projeto de navegação enquanto

\footnotetext{
${ }^{4}$ Citação original: “[...] pueden encontrar sus genealogías en voces de mujeres del pasado.” (NAVARRO SALAZAR, 2006, p. 218)
} 
ainda viviam em Portugal. Isso certamente está relacionado à posição que essa senhora ocupava na corte portuguesa, já que era filha de um importante marinheiro e governador da ilha de Porto Santo. Tão raros são os registros sobre tal personagem que, embora pertencente à nobreza - mesmo que decadente -, não há documentos que apontem de modo preciso sua vida e seu desfecho histórico.

Escamoteada pela historiografia, Felipa veio a despertar o interesse de romancistas estadunidenses nas décadas finais do século XX. A ela, o escritor Stephen Marlowe dedica várias cenas de sua metaficção historiográfica plena The memoirs of Christopher Columbus (1987). Já como protagonista, é retratada pela romancista novaiorquina Paula DiPerna em sua obra The discoveries of Mrs. Christopher Columbus - his wife's version (1994). Para criar sua diegese, a romancista ignora o fato histórico da morte de sua protagonista e a faz cruzar o oceano Atlântico com o marido, Cristóvão Colombo, em 1492, o que a leva a descobrir não só quem, de fato, era esse sujeito, como também um novo mundo e, mais do que isso, a si mesma como mulher. A narrativa está disposta em forma de diário, parodiando a escrita oficial, no qual a Sra. Colombo registra as suas próprias impressões sobre a viagem, os tripulantes e os nativos “descobertos” na América. Assim, a protagonista aponta: “[...] o almirante escreve muito do que acontece, eu também, embora não tenha contado a ele. Meu registro é de mim mesma, para anotar nossa impressão em uma viagem que ninguém fez antes, para flutuar um quadro no mar em movimento de minha mente, ao qual pensamentos aleatórios podem se agarrar"5 (DIPERNA, 1994, p. 2).

Esse novo diário contém, pois, as mesmas informações presentes no registro masculino oficial, mas está escrito sob o atento, perspicaz, curioso e feminino olhar de Felipa. Tal olhar descobrirá um "Novo mundo", uma nova personalidade do marido e, mais do que isso, um sentido para sua própria existência.

Outra personagem central nesse contexto é, sem dúvida, a jovem Beatriz Enríquez de Harana - mãe do segundo filho de Colombo. Ela vivia em Córdoba e acolheu Colombo em sua casa durante toda a trajetória do marinheiro em busca do apoio dos reis católicos que ele necessitava para realizar a viagem rumo ao ocidente para chegar ao oriente. $\mathrm{O}$

\footnotetext{
${ }^{5}$ Citação original: “the Admiral writes down much that happens, so do I, though I haven't told him. My record is my own, to keep note of our impression on a trip no one has made before, to float a frame on the moving sea of my mind to which random thoughts can cling." (DIPERNA, 1994, p. 2).
} 
nome de Beatriz nem sequer é mencionado na primeira biografia de Colombo, cujo autor, Fernando Colombo, é filho de ambos.

Como pessoa que esteve muito próxima de Colombo na fase em que buscava o apoio dos Reis Católicos, Fernando e Isabel, para realizar essa inusitada viagem, e mesmo após a efetivação dessa, a jovem de Córdoba é mencionada nas biografias de Colombo do século XX, como, por exemplo, na de Jacob Wassermann (1930), na de De la Torre y Del Cerro (1933), na de Madariaga (1947), na de Manzano Manzano (1964), entre outras. Como personagem de ficção, Beatriz Enríquez de Harana é configurada em várias obras, entre elas podemos mencionar a estadunidense Columbus and Beatriz (1892), de Constance Goddard DuBois - primeira narrativa de autoria feminina sobre o “descobrimento" da América -; a paraguaia Vigilia del Almirante (1992), de Augusto Roa Bastos - que a apresenta como um ser altamente erotizado -; e a espanhola Colón a los ojos de Beatriz (2000), de Pedro Piqueras - uma narrativa que se encaminha, lentamente, para os moldes do romance histórico contemporâneo de mediação (FLECK, 2007-2017).

Fleck (2017) define o romance histórico contemporâneo de mediação como a modalidade mais recente de escrita híbrida de história de ficção, pertencente à fase crítica da trajetória do gênero romance histórico, mas sem contemplar as características predominantes no novo romance histórico latino-americano ou na metaficção historiográfica. Segundo o autor, as principais características dessa modalidade de romance histórico contemporâneo são:

a) uma releitura crítica verossímil do passado, que busca a construção da verossimilhança - em grande medida deixada de lado pelas narrativas do novo romance histórico hispanoamericano e da metaficção historiográfica -, e se afasta dos parâmetros dos cânones europeus, os quais primavam pelo engrandecimento dos heróis do passado e por ensinar a história ao leitor;

b) uma narrativa linear do evento histórico recriado que, apesar de ainda manipular o tempo da narrativa por meio de analepses e prolepses, não se utiliza de anacronias exageradas ou sobreposições de tempos históricos ou narrativos distintos, como acontece nas modalidades da metaficção histórica e do novo romance histórico hispano-americano; c) foco narrativo geralmente centralizado no ex-cêntrico (HUTCHEON, 1991), evidenciando perspectivas "vistas de baixo" (com base em Sharpe, 1992), privilegiando 
visões marginais, sem centrar-se em grandes personagens da história - como o fazem muitos novos romances históricos e algumas metaficções historiográficas;

d) linguagem simples, fluída, de uso cotidiano - em oposição ao barroquismo e ao experimentalismo linguístico presente em muitos novos romances históricos e em algumas metaficções historiográficas;

e) emprego de estratégias escriturais bakhtinianas, como a dialogia, a polifonia e a paródia;

f) presença de recursos metaficcionais/metanarrativos.

Em Colón a los ojos de Beatriz (2000), de Pedro Piqueras, romance espanhol do século XX, a criticidade está no ato de se dar a uma perspectiva feminina a ótica da releitura da história pela ficção. Contudo, em certos momentos da diegese, o tradicionalismo sobressai-se na configuração dos heróis nacionais - como é o caso dos reis Isabel e Fernando -, e a protagonista, mesmo na arte literária, segue presa às convenções sociais que a emudeceram no discurso historiográfico. Beatriz Enríquez de Harana, como voz enunciadora do discurso, revela: “[...] sempre estive perto da glória mundana como quem observa a dança por detrás das cortinas"6 (PIQUERAS, 2000, p. 17 - tradução nossa). Assim, transparece-se o silenciamento histórico infligido à voz da mulher, em especial, de uma personagem histórica que viveu junto a Colombo todos os avatares de sua empreitada em busca de um novo caminho às Índias via oeste.

Desse período histórico referente ao "descobrimento" da América, há ressonâncias nos registros oficiais do nome de outra figura de representação feminina que foi subjugada no discurso historiográfico hegemônico europeu: a nativa taína Anacaona, esposa do chefe da tribo taína, que habitava a ilha de Guanahaní, onde chegou Colombo em 12 de outubro de 1492. Após a prisão de seu marido pelos espanhóis, acusado pelo ataque ao Fuerte Navidad, e o extermínio dos 39 espanhóis aí deixados por Colombo quando de sua primeira viagem, bem como após a morte do irmão de Anacaona - outro importante cacique taíno -, ela assume o comando de sua tribo e, em certa ocasião de comemoração entre as tribos, é acusada de conspiração pelos conquistadores espanhóis e, junto a vários nobres taínos, é executada aos seus 29 anos.

\footnotetext{
${ }^{6}$ Citação original: “[...] siempre estuve cerca de la gloria mundana como quien observa la danza tras unas cortinas." (PIQUERAS, 2000, p. 17).
} 
Um dos únicos registros sobre a execução de Anacaona e sua tribo foi feito por Frei Bartolomeu de Las Casas, frade dominicano espanhol, considerado um defensor dos indígenas. Em sua obra La Brevísima relación de la destrucción de las indias (1552 [2011]), Las Casas relata suas vivências junto aos exploradores espanhóis durante as viagens ao "Novo Mundo", inclusive nos primeiros contatos que os espanhóis tiveram com os nativos americanos no período da conquista e colonização da América.

Segundo Las Casas (1552 [2011]), quando Colombo chegou à América, foi em Guanahaní (Isla La Española), território da atual República Dominicana e do Haiti, que teve o primeiro contato com os povos nativos. Nessa ilha, havia cinco reinos principais, com cinco chefes, e quase todos obedeciam a outros senhores. Um desses reinos chamavase Xaraguá, localizado no centro da ilha, que se sobressaía aos outros pela polidez, formosura e beleza de seu povo, além da presença de senhores e nobres em grande número. Seu rei e senhor chamava-se Behechio, cuja irmã se chamava Anacaona. Esses dois irmãos prestaram grandes serviços aos reis de Castela e imensos benefícios aos cristãos, salvando-os de muitos perigos de morte. Depois da morte de Behechio, Anacaona assumiu o reino.

Continua Las Casas (1552 [2011]) que, certa vez, quando estabelecidas as colônias espanholas no território da Ilha La Española, o governador, Nicolas Ovando, que fora designado pela corte para governar esta região, dizimou a tribo chefiada por Anacaona:

Certa vez, aqui chegou o governador que governava esta ilha, com sessenta cavaleiros e mais trezentos peões, sendo que apenas os que estavam a cavalo bastavam para destruir toda a ilha e o continente, e mais de trezentos chefes vieram ao seu chamado, seguros, os quais ele mandou colocar a maioria dentro de uma casa de palha muito grande por engano e, quando eles entraram, ordenou que ateassem fogo e os queimassem vivos. A todos os outros alancearam e mataram muita gente com a espada, e a chefe Anacaona, para honrá-la, enforcaram ${ }^{7}$ (LAS CASAS, 1552 [2011], p. 28 - tradução nossa).

De maneira distinta aos relatos de Las Casas, Hernán Cortés (1485-1547), um dos exploradores espanhóis enaltecidos pela historiografia tradicional, menciona a autóctone

\footnotetext{
${ }^{7}$ Citação original: “Aquí llegó una vez el gobernador que gobernaba esta isla con sesenta de caballo y más trecientos peones, que los de caballo solos bastaban para asolar a toda la isla y la tierra firme, y llegáronse más de trecientos señores a su llamado, seguros, de los cuales hizo meter dentro de una casa de paja muy grande los más señores por engaño, y metidos les mandó poner fuego y los quemaron vivos. A todos los otros alancearon y metieron a espada con infinita gente, y a la señora Anacaona, por hacelle honra, ahorcaron" (LAS CASAS, 1552 [2011], p. 28).
} 
Anacaona e o genocídio de sua tribo de maneira irrisória em suas Cartas de Relación $(1519,1520,1522,1524,1526)$, descrevendo-a como a "reina viuda de Haiti" (rainha viúva do Haití) no seguinte excerto:

'Não vim aqui para cultivar a terra como camponês', respondeu Cortés, 'mas para procurar ouro.' Isto, no entanto, Cortés aceitou pouco depois, do mesmo Ovando, uma divisão de índios em Daiguao, e o escrivão da recém-fundada cidade de Azua, e o escritório da recém-fundada cidade de Azua, tornando-se imediatamente credor de maiores doações por seus serviços na guerra que Diego Velázquez liderava contra Anacaona, rainha viúva do Haiti ${ }^{8}$ (CORTÉS, 15191526 [2019], p. 10-11 - tradução nossa).

A atuação da nativa Anacaona foi, frequentemente, subjugada pela historiografia oficial, a partir de discursos propagados por homens exploradores europeus da época, como podemos verificar no Diário de bordo (1492-1493) e nas Cartas (1493), de Cristóvão Colombo (1451-1506), e as Cartas de Relación (1519, 1520, 1522, 1524, 1526), de Hernán Cortés (1485-1547). Sendo esses alguns dos exemplos de registros oficiais que mencionam infimamente a figura de Anacaona, personagem feminina líder de uma tribo taína que foi assassinada pela atuação colonizadora europeia na América.

A história dessa autóctone foi reavivada pela ficção a partir do final do século XX, ao se ressignificar tal personagem de extração histórica como uma forma de demonstrar que a história hegemônica, vivida e narrada apenas por uma mínima parcela masculina detentora do poder, tem resguardada, silenciada e ocultada a ação de sujeitos que desempenharam um papel fundamental na forma como se deram os fatos. Esses sujeitos, uma vez fora do círculo do poder e dos interesses, são majoritariamente anulados pela escrita a serviço, primordialmente, da elite dominadora. Assim, Anacaona reaparece, séculos após seu enforcamento, como protagonista de vários romances, entre os quais, destacamos Anacaona y las tormentas (1994), do colombiano Luis Darío Bernal Pinilla, Anacaona: Golden Flower, Haiti, 1490 (2005), da haitiana Edwidge Danticat, e Anacaona: la última princesa del Caribe (2017), do espanhol Jordi Díez Rojas.

Sem dúvidas, houve outras mulheres de destaque no período do "descobrimento" da América. Contudo, mencionamos apenas essas três personagens e suas participações

\footnotetext{
${ }^{8}$ Citação original: “'Yo no vine aquí para cultivar la tierra como un labriego,' le contestó Cortés, 'sino para buscar oro.' Esto sin embargo, Cortés aceptó poco después del mismo Ovando un repartimiento de indios en Daiguao, y la escribanía de la recien-fundada villa de Azua, haciéndose muy pronto acreedor á mayores mercedes por sus servicios en la guerra que contra Anacaona, reina viuda de Haití dirigía á la sazón Diego Velazquez" (CORTÉS, 1519-1526 [2019], p. 10-11).
} 
inquestionáveis no destino da história como exemplos do silenciamento de vozes femininas no discurso historiográfico hegemônico.

Quando se passa à história do período da conquista da América, outra vez se ressaltam nomes de "grandes" homens, como os de Hernán Cortés, Francisco Pizaro, Pedro de Valdivia e muitos outros "ilustres conquistadores" e cronistas das Índias. Nome feminino de destaque inegável nesse período é o da nativa Malintzin, Malinche, ou ainda Doña Marina, uma nativa escravizada que foi dada de presente à comitiva de Hernán Cortés em sua trajetória rumo à conquista do maior império da América pré-colombiana: o império asteca. O relevante papel de Malinche como intérprete, negociadora e, por que não dizer, conselheira cultural de Cortés, não pôde deixar de ser mencionado entre as narrativas heroicas dos espanhóis em seus procedimentos de conquista. Assim também ocorre com a nativa Inca, a princesa Palla Chimpu Ocllo, que se casou com o conquistador espanhol Sebastián Garcilaso de la Vega y Vargas e se tornou, assim, mãe do renomado Inca Garcilaso de la Vega, considerado o primeiro escritor mestiço da América hispânica.

Malinche é personagem importante de Xicoténcatl $^{9}$ (1826), o primeiro romance histórico escrito anonimamente na América Latina. Nessa narrativa, ela divide o espaço protagônico com o conquistador espanhol Hernán Cortés e com o casal Xicoténcatl e Teutila, heróis da resistência à conquista do México. A apoteótica história dessa autóctone náhuatl também conquistou a simpatia do romancista inglês Alexander Baron (19171999), que, em 1954, escreveu o volumoso romance The golden princess, conferindo-lhe o protagonismo na diegese desenvolvida. Esse romance inglês foi traduzido ao espanhol pela EMECE editores, Buenos Aires, em 1955, e uma segunda edição foi realizada em 1963, com o título de La princesa de oro. Escritores contemporâneos de diferentes países, em diferentes gêneros, também se dedicaram a reler a trajetória dessa mulher que conseguiu despertar os mais variados sentimentos nos descendentes de sua tribo e nação, como também fora desse universo. Entre eles, citamos, como exemplo apenas, a renomada romancista mexicana Laura Esquivel que lançou, em 2006, o romance Malinche, no qual se relata uma nova versão sobre o intenso romance vivido entre a nativa e o conquistador espanhol.

É interessante considerar, no que se refere ao período do "descobrimento" e conquista da América e à participação das mulheres em vários episódios marcantes da

\footnotetext{
${ }^{9}$ Traduzido para o português pela primeira vez em 2020, por Gilmei Francisco Fleck.
} 
época, o que expõe Manuel Fernández Álvarez em sua obra Casadas, monjas, rameras, y brujas: la olvidada historia de la mujer española en el Renacimiento (2002), um estudo que analisa a situação da mulher no período em que viveram essas importantes mulheres acima citadas. O que se pode verificar ao ler esta obra é que o Renascimento foi, especialmente na Espanha, um tempo em que a mulher permaneceu ainda na sombra, destacando-se somente em alguns casos excepcionais, como o de Isabel, a Católica, e os de outras poucas senhoras cujos feitos extraordinários ficaram em evidência.

As mulheres estavam, em geral, destinadas ao silêncio, à exclusão e ao descaso, pois o espaço público era, exclusivamente, masculino, cabendo a elas o recato, quando casadas ou reclusas em algum convento, ou o trânsito às margens do sistema altamente discriminador. Quando sua situação era semelhante à da segunda companheira de Colombo - a judia conversa Beatriz Enríquez de Harana, com quem Colombo nunca chegou a se casar, embora também tenha tido com ela um filho, Fernando Colombo -, as possibilidades de alcançar alguma notoriedade estavam totalmente excluídas.

Contudo, conforme registra Salvador de Madariaga, um dos mais importantes biógrafos de Colombo: "Beatriz foi a única flor em seu caminho espinhoso" (MADARIAGA, 1947, p. 229 - tradução nossa). Também o biógrafo alemão Jacob Wasserman (1930, p. 52) refere-se à jovem Beatriz e afirma: “[...] dela recebeu Colombo, sem dúvida, alentos e cuidados; seu coração foi quiçá o único que realmente possuiu naquele período sombrio, porque em seu próprio testamento a recomenda encarecidamente a seus herdeiros como a pessoa a quem está muito obrigado"11 (MADARIAGA, 1947, p. 229 - tradução nossa).

Registros sobre a importância da participação dessa mulher na trajetória de Colombo são, pois, feitos já no século XX, quando se destacam a sua relevância e atuação decisiva na permanência de Colombo na Espanha, perseverando na busca de auxílio ao projeto idealizado por conta do apoio e do acolhimento de Beatriz.

Nessa época do fim do século XV e início do XVI - quando se dão os fatos históricos aqui mencionados -, a mulher era ainda celebrada na literatura como a musa

\footnotetext{
${ }^{10}$ Citação original: "Beatriz fué la única flor en su espinoso camino” (MADARIAGA, 1947, p. 229).

${ }^{11}$ Citação original: “[...] de ella recibió, sin duda, Colón alientos y cuidados; su corazón fue quizá el único que realmente poseyó en aquel período sombrío, porque en su mismo testamento la recomienda encarecidamente a sus herederos como a persona a la que está muy obligado." (MADARIAGA, 1947, p. 229).
}

Revista Escritas do Tempo - v. 3, n. 8, mai-ago/2021 - p. 244-262 
dos heróis dos romances de cavalaria, aparecendo como ideal de perfeição e, sob todos os aspectos, idealizada. Ou, ao contrário, era vista como uma das criaturas mais temíveis e abomináveis, como as bruxas e as alcoviteiras, que também merecem destaque em boa parte das obras literárias desse período. Se nos reportarmos uma vez mais a Fernández Álvarez para situar melhor, nesse sistema, as personagens europeias Isabel, Felipa e Beatriz, vemos que existiam, para a mulher desse tempo e espaço, “[...] duas valorações distintas, porque existem dois modos de medir também distintos: frente às damas enaltecidas (as grandes senhoras da Corte), as mulheres simples da vida corrente. Diante da rendida admiração, o brutal desprezo"12 (ÁLVAREZ, 2002, p. 77 - tradução nossa).

Um sistema como esse, mesmo na Europa, excluía a mulher da atuação pública, do acesso ao conhecimento, das possibilidades de se desenvolver intelectualmente ou mesmo de estabelecer relações por si só, condicionando-a à servidão, seja dos pais, dos irmãos ou dos maridos que lhes fossem designados. Conforme expressa Lucía Guerra (2007, p. 9-10 - tradução nossa): “em uma sociedade patriarcal que negou a práxis do poder às mulheres, elas receberam como substitutos as rocas e almofadas de fiar com a finalidade de mantê-las presas aos trabalhos domésticos" ${ }^{" 13}$. Assim vivia a quase totalidade das mulheres ainda no Renascimento Europeu.

Quanto ao período da "descoberta" e conquista da América - considerado como o início da Era Moderna -, a condição da mulher não sofreu grandes alterações. O "Novo Mundo" era um espaço de conquista e aventura para os homens e, da mesma forma, espaço discursivo da construção de imagens heroicizadas que, em primeiro plano, deveriam edificar os próprios cronistas diante de seus superiores e, desse modo, erigi-los como modelos de bravura e coragem diante de toda a sociedade.

Modelo de escrita e escritor, nesse sentido, é, pois, o Diário de bordo (1492-1493), de Cristóvão Colombo: texto responsável pela disseminação das primeiras imagens da terra e das gentes do nosso continente no imaginário europeu do fim século XV. O crítico Marcelino Menéndez Pelayo (1925), em seus estudos sobre o teatro de Lope de Vega - o qual inclui a obra dramática intitulada El Nuevo Mundo descubierto por Cristóbal Colón

\footnotetext{
${ }^{12}$ Citação original: “[...] dos valoraciones distintas, porque hay dos varas de medir también distintas: frente a las damas encumbradas (las grandes señoras de la Corte), las mujeres sencillas de la vida corriente. Frente a la rendida admiración, el brutal desprecio.” Fernández Álvarez (2002, p. 77).

${ }^{13}$ Citação original: "en una sociedad patriarcal que les ha negado la práxis del poder a las mujeres, ellas han recibido como sustitutos las ruecas y almohadillas con el fin de mantenerlas atadas a las labores domésticas." (LUCÍA GUERRA, 2007, p. 9-10).
} 
-, registra, a respeito do navegante, o fato de:

[...] ter sido ele mesmo o seu primeiro historiador em seu diário e em suas cartas, onde não apenas se admira a espontânea eloquência de uma alma inculta, a quem grandes coisas ditam grandes palavras, expondo-as a alturas mais elevadas do que toda retórica pelo poder da emoção sincera, mas neles o homem aparece por inteiro, com os traços mais complexos de sua personalidade. ${ }^{14}$ (MENÉNDEZ PELAYO, 1949, p. 310 - tradução nossa).

A esse respeito cabe mencionar, também, os estudos críticos acerca dos discursos narrativos da conquista da América realizados por Beatriz Pastor (1983), nos quais a autora busca explicar o processo de construção da imagem da realidade americana efetuado pelos conquistadores. Em sua obra Discurso narrativo de la conquista de América (1983), a autora parte do discurso mitificador encontrado nas Cartas de Colombo, passando pelo modelo de conquistador europeu estampado nas Cartas de relaciones, de Hernán Cortés, indo ao discurso de rebelião registrado nas diversas crônicas que relatam a história de Lope de Aguirre, que encarna "[...] uma inversão sistemática das características do modelo"15 (PASTOR, 1983, p. 42 - tradução nossa). Na sua análise dos discursos do "descobrimento" da América, Pastor (1983, p. 47 - tradução nossa) registra, por exemplo, a respeito da escrita de Colombo, que, desde o primeiro instante: "Colombo não dedicou suas faculdades a ver e a conhecer a realidade concreta do Novo Mundo, mas a selecionar e a interpretar cada um de seus elementos de tal forma que lhe fosse possível identificar as terras recém-descobertas com o modelo imaginário daquelas que ele estava destinado a descobrir" ${ }^{\prime 16}$.

Observamos, assim, que a pesquisadora se refere ao processo de seleção e manipulação dos dados sobre o "Novo Mundo", registrados pelos conquistadores, como sendo um processo de "ficcionalização" da realidade. Já a estudiosa espanhola Celia Fernández Prieto (2003, p. 156) menciona ainda que, no caso específico de Colombo e Cortés, não houve ficcionalização, houve fraude, houve mentira: “[...] justamente esse

\footnotetext{
${ }^{14}$ Citação original: "[...] haber sido él mismo su primer historiador en su diario y sus cartas, donde no sólo se admira la espontánea elocuencia de un alma inculta, a quien grandes cosas dictan grandes palabras, levantándola a alturas superiores a toda retórica por el poder de la emoción sincera, sino que aparece el hombre entero, con los complejísimos rasgos de su personalidad" (MENÉNDEZ PELAYO, 1949, p. 310). ${ }^{15}$ Citação original: "[...] una inversión sistemática de los rasgos del modelo" (PASTOR, 1983, p. 42).

${ }^{16}$ Citação original: "Colón no dedicó sus facultades a ver y conocer la realidad concreta del Nuevo Mundo sino a seleccionar e interpretar cada uno de sus elementos de modo que le fuera posible identificar las tierras recién descubiertas con el modelo imaginario de las que él estaba destinado a descubrir" (PASTOR, 1983, p. 47).
} 
uso fraudulento dos discursos de verdade põe em relevo como os conquistadores espanhóis contavam a história de acordo com seus interesses políticos, silenciando tudo o que pudesse trazer-lhes o descrédito de seus superiores"17. Desse modo, os registros feitos exclusivamente pelos conquistadores brancos europeus sobre toda essa parte de nossa história voltam-se à edificação heroica do homem por si mesmo, já que era ele quem dominava o processo de escrita naquela época. Fica evidente que tais registros eurocêntricos e falocêntricos tendem a excluir fatos relevantes que envolvam personagens nativas ou mulheres que também se destacaram ao lado dos heróis sacralizados nas escritas que perduraram até nossos dias.

As poucas mulheres que chegaram a cruzar o Atlântico foram, em sua grande maioria, enviadas para constituírem famílias cristãs nessas terras "selvagens", seguindo, pois, as mesmas normas rígidas de conduta servil e cristã que levavam na Espanha ou Portugal naquela época. Esse contexto específico é plasmado com muita originalidade pela romancista brasileira Ana Miranda, que, em sua obra Desmundo (1996), relata a trajetória da personagem Oribela - órfã enviada à colônia pela rainha a fim de constituir família com algum colono já instalado nas novas terras anexadas à coroa portuguesa. Embora Oribela não seja uma personagem histórica, ela é metonímia de todas as órfãs portuguesas que, historicamente, tiveram esse destino no início do século XVI: foram deportadas para desposar os colonos aventureiros nas terras do Brasil e formar famílias cristãs entre a população majoritariamente masculina que já se relacionava sexualmente com as nativas.

Nos estudos de Lucía Guerra (2007, p. 12 - tradução nossa), voltados à relação entre mulher e escrita, menciona-se que:

No estranho papel de um subalterno, que também é sublime, conforme os mitos que o qualificam como suplemento espiritual para a árdua vida dos homens dedicados ao trabalho e à política, a relação da mulher com o poder tem sido marcada por laços de afeto e relações interpessoais. Por trás do afetivo, no entanto, repousa outra instância do poder, posto que as instituições do matrimônio e da família em uma reiteração das organizações da Igreja e do Estado, postulavam o Pai como a figura Suprema. ${ }^{18}$

\footnotetext{
${ }^{17}$ Citação original: “[...] precisamente este uso fraudulento de los discursos de verdad pone de relieve como los conquistadores españoles contaban la historia de acuerdo con sus intereses políticos, silenciando cuanto podía acarrearles desprestigio ante sus superiores" (PRIETO, 2003, p. 156).

${ }^{18}$ Citação original: "En el extraño papel de un subalterno que es también sublime, según las mitificaciones que la califican como el suplemento espiritual para la ardua vida de los hombres dedicados al trabajo y la política, la relación de la mujer con el poder ha estado marcada por lazos de afecto y relaciones
} 
Algumas poucas mulheres, contudo, acabaram vivendo nesse continente um destino diferente. María Rosa Rojo, em sua edição da obra Lucía Miranda (2007), de Eduarda Mansilla, ao comentar a importância da retomada dessas escritas de autoria feminina do século XIX na contemporaneidade, e, em especial, sobre a trajetória histórica dessa mulher - Lucía Miranda - na Argentina, e a sua significativa recriação na ficção de Eduarda Mansilla e outras escritoras, destaca:

Com 'Lucía', a 'Cativa Branca', a mulher cobiçada por dois chefes indígenas, é encenado um verdadeiro 'mito de origem' protonacional, que tenta explicar ou justificar com nuances diversas, em suas diversas recriações, a possibilidade de integrar ou não as etnias originárias, o papel das mulheres na fundação da sociedade e seu caráter como mediadoras forçadas entre mundos heterogêneos, ou entre Natureza e Cultura ${ }^{19}$ (LOJO, 2007, p. 11 - tradução nossa).

Em outro sentido, é fácil compreender que o âmbito de produção do discurso historiográfico, imbuído do teor de veracidade que se buscava, especialmente em sua fase rankeana-tradicional, dificilmente chegou a ser um ambiente no qual a autoria feminina encontrasse algum espaço de manifestação. Este espaço, por meio do método científico e ancorado na objetividade e no respaldo da certificação das fontes, sempre fora de domínio exclusivo de autoridade centrada na voz masculina. No espaço ficcional, a situação nunca foi muito diferente, dado que, segundo menciona Lucía Guerra (2007, p. 7), até a década de 1970, existia, na cultura ocidental, um preconceito com relação à literatura de autoria feminina. Devido a isso, e para que suas escritas ganhassem atenção, principalmente da crítica, muitas mulheres, quando escreviam, faziam-no sob algum pseudônimo masculino.

A crítica feminista, surgida como consequência do movimento feminista que ocorreu ao redor da década de 1960, especialmente nos Estados Unidos e na França, dedica-se, na contemporaneidade, entre outras importantes atividades, a realizar uma série de pesquisas que revelem as tantas injustiças sofridas pelas mulheres durante a

interpersonales. Tras lo afectivo, sin embargo, yacía otra instancia del poder, puesto que las instituciones del matrimonio y la familia, en una reiteración de las organizaciones de la iglesia y el Estado, postulaban al Padre como la figura Suprema” (LUCÍA GUERRA, 2007, p. 12).

${ }^{19}$ Citação original: "Con 'Lucía', la 'Cautiva blanca', la prenda codiciada por dos caciques indígenas, se pone de escena un verdadero 'mito de origen' protonacional, que intenta explicar o justificar con matices diversos, en sus distintas recreaciones, la posibilidad de integrar o no a las etnias originarias, el papel de las mujeres en la fundación de la sociedad y su carácter de forzosas mediadoras entre mundos heterogéneos, o entre Naturaleza y Cultura" (LOJO, 2007, p. 11). 
vigência quase exclusiva do poder patriarcal nas áreas da esfera pública até poucas décadas passadas.

Com relação à escrita de autoria feminina, estas pesquisas buscam, num primeiro momento, resgatar textos nunca valorizados pela crítica de caráter androcêntrico e tornálos conhecidos do público leitor e, em segundo lugar, evidenciar a densidade e complexidade desses textos, elaborados, conforme comenta Guerra, "desde um lugar outro: o da subordinação das mulheres"20 (GUERRA, 2007, p. 8 - tradução nossa). Essa jornada da valorização da escrita de autoria feminina tem sido árdua desde seus princípios e tem, ainda hoje, muito a revelar sobre o valor da escrita e sobre a própria história da mulher em nossa sociedade.

Se pensarmos na escrita híbrida de história e ficção na qual se constitui o romance histórico sob esta perspectiva da crítica feminista, não será difícil imaginar esse árduo caminho percorrido pelas escritoras para que suas obras, inscritas especialmente neste contexto de expressão dessa modalidade de romance, viessem a ter o merecido reconhecimento.

Apesar de contarmos hoje com um considerável corpus teórico sobre o romance histórico, pouco se tem escrito sobre a autoria feminina nesse universo ficcional. Segundo comenta Cunha, na já vasta produção crítica, "surpreende o abandono quase total em que se encontra a narrativa histórica das escritoras, pois, embora o número de obras indique o contrário, parece que ainda prevalece a opinião de que a história não é um dos seus temas preferidos"21 (CUNHA, 2004, p. 12 - tradução nossa). Nesse contexto já desfavorável, cabe lembrar que, em especial, as narrativas de autoria feminina sobre o "descobrimento" e conquista da América não chegaram a ocupar qualquer espaço de destaque em suas primeiras tentativas.

A primeira obra escrita por uma mulher que trata dessa temática é o romance estadunidense "Columbus and Beatriz", escrito no simbólico ano de 1892, data de comemoração do IV centenário da primeira viagem de Colombo à América. Uma escrita de autoria feminina em cujo prefácio a autora declara:

\footnotetext{
${ }^{20}$ Citação original: “desde un sitio otro: el de la subordinación de la mujer” (GUERRA, 2007, p. 8).

${ }^{21}$ Citação original: "surpreende o abandono quase total em que se encontra a narrativa histórica das escritoras, pois, embora o número de obras indique o contrário, parece que ainda prevalece a opinião de que a história não é um dos seus temas preferidos" (CUNHA, 2004, p. 12).
} 
O propósito deste trabalho é tentar reparar a injustiça que a história cometeu com relação a uma mulher nobre e de prolongado sofrimento. Negou-se a Beatriz Enríquez sua posição de direito como esposa de Colombo nos escritos de Humboldt e Irving até aos do turista que publicou suas impressões de uma estadia de duas semanas na Espanha; discorreu-se muito sobre a relação ilícita de Colombo com uma senhora de Córdoba em narrativas imparciais e com relatos zombeteiros $^{22}$ (DUBOIS, 1892, p. 4 - tradução nossa).

Vemos, pois, que o processo de escrita de DuBois faz-se sob um propósito definido e seguro: ressaltar a participação da mulher nos eventos históricos. Com relação às criações literárias que buscam evidenciar a importante participação das mulheres de Colombo em sua jornada rumo à imortalização de seu nome pela consagração histórica alcançada, é importante ressaltar que a liberdade da ficção permite inusitadas versões, como comentamos que ocorre com Paula DiPerna que, em seu romance contemporâneo The discoveries of Mrs. Christopher Columbus: his wife's version (1994), simplesmente ignora o fato de que Felipa realmente morreu poucos anos após seu casamento com Colombo e faz dela voz enunciadora do discurso de sua obra.

Tal estratégia lhe permite fazer da esposa de Colombo o foco narrativo de uma trama que se estende para além do real período de sua vida, imprimindo a toda a trajetória da viagem de Colombo, descrita em seu Diário de bordo (1492-1493), uma visão feminina, alcançada pela paródia do discurso histórico de Colombo numa narrativa ficcional emocionante e cativante.

$\mathrm{Na}$ contemporaneidade, vê-se a retomada desses períodos históricos, com destaque às "desconhecidas" protagonistas femininas e suas ações relevantes nessa empreitada. Exemplos dessas escritas de mulheres no universo literário latino-americano podem ser as obras mencionadas de Eduarda Mansilla, com Lucía Miranda (1860), reeditada por María Rosa Lojo em 2007; de Ana Miranda, com Desmundo (1996); de María Rosa Lojo, com Amores insólitos de nuestra historia (2001); de Isabel Allende, com Inés del Alma mía (2003); de Edwidge Danticat, com Anacaona: Golden Flower, Haiti 1490 (2005); de Laura Esquivel, com Malinche, (2006), entre tantas outras.

Se nos registros históricos não houve espaço para a expressão das vozes das mulheres, tais vozes, no território da arte ficcional contemporânea, manifestam-se de

\footnotetext{
${ }^{22}$ Citação original: "The object of this work is to attempt the reparation of an injustice which history has done to a noble and long-suffering woman. Beatriz Enriquez has been denied her lawful position as the wife of Columbus by writers from Humboldt and Irving to the tourist who publishes his impressions of a few week's sojourn in Spain; and the illicit connection of Columbus with a beautiful lady of Cordova has been expatiated upon in every tone of impartial narrative and jesting allusion" (DUBOIS, 1892, p. 4).
} 
forma aberta, liberal e atemporal. Como faz a personagem de Isabel Allende, Inés Suares - protagonista do romance Inés del alma mía -, ao revelar que, antes de vir à América, "[...] vivia raivosa comigo e com o mundo por ter nascido mulher e estar condenada à prisão dos costumes" ${ }^{23}$ (ALLENDE, 2008, p. 28 - tradução nossa).

No espaço discursivo ficcional romanesco, essas mulheres - feitas personagens de extração histórica - são, nas narrativas de autoria feminina, libertadas das amarras que lhes impediam de se expressar em sua própria época, podendo, pela liberdade da ficção, revelar outras tantas "verdades", tantas diferentes visões e perspectivas dos fatos por elas vivenciados, porém omitidas pelo discurso histórico hegemônico masculino. Assim, a narrativa híbrida de autoria de mulheres rompe barreiras de tempo e espaço a fim de buscar a representação que, no passado, não lhes foi outorgada pela historiografia.

Nas produções híbridas de história e ficção contemporâneas, o discurso artístico enfrenta-se com o passado histórico de forma direta, pois os romancistas têm se mostrado cada vez mais conscientes de que tanto história quanto literatura são discursos, construídos a partir da ótica de um produtor, são produtos de linguagem, feitos e manipuláveis, e de que não há verdades absolutas sobre o passado, mas, sim, diferentes perspectivas desse. Logo, literatura e história interpenetram-se pelo manejo do tempo e pelas técnicas narrativas de que fazem uso. Elas interagem e se entrosam por serem formas de linguagem, desse modo, de acordo com Linda Hutcheon (1991), são práticas discursivas, que possuem seu objeto nas atividades humanas. Além disso, "hoje pensar historicamente é pensar crítica e contextualmente" (HUTCHEON, 1991, p. 121). Este pensamento realiza dois movimentos simultâneos, pois “[...] reinsere os contextos históricos como sendo significantes, e até determinantes, mas, ao fazê-lo, problematiza toda a noção de conhecimento histórico." (HUTCHEON, 1991, p. 122).

Tal paradoxo consolida o desejo de repensar o passado oculto das mulheres. Nesse sentido, a protagonista da obra de Isabel Allende menciona: “[...] devo relatar minha versão do acontecido para deixar memória dos trabalhos que nós mulheres temos passado no Chile e que costumam escapar dos cronistas, por destros que sejam"24 (ALLENDE,

\footnotetext{
${ }^{23}$ Nossa tradução livre: “[...] vivía rabiosa conmigo y con el mundo por haber nacido mujer y estar condenada a la prisión de las costumbres" (ALLENDE, 2008, p. 28).

${ }^{24}$ Citação original: “[...] debo relatar mi versión de lo acontecido para dejar memoria de los trabajos que las mujeres hemos pasado en Chile y que suelen escapar a los cronistas, por diestros que sean" (ALLENDE, 2008, p. 80).
} 
2008, p. 80 - tradução nossa). Vemos, pois, que o discurso ficcional se enfrenta com o historiográfico, evidenciando a visão tendenciosa deste de apenas registrar a participação do homem na história, excluindo a mulher dos relatos oficiais. Cabe, pois, ao discurso ficcional contemporâneo a tarefa de explorar outras perspectivas sob as quais o passado também possa ser imaginado e registrado, para que as mulheres saiam do anonimato histórico e ganhem protagonismo na ficção que ressignifica o passado de submissão e silenciamento ao qual o registro tradicional da historiografia as condenou.

\section{Referências}

ALLENDE, I. Inés del alma mía. Buenos Aires: Debolsillo, 2008.

CIPLIJAUSKAITÉ, B. La novela femenina contemporánea (1970-1985). Hacia una tipología de la narración en primera persona. Barcelona: Anthropos, 1988.

CUNHA, G. (Ed.). La narrativa histórica de escritoras latinoamericanas. Buenos Aires: Corregidor, 2004.

DANTICAT, E. Anacaona: Golden Flower, Haiti 1490. New York: Scholastic Inc., 2005.

DiPERNA, P. The discoveries of Mrs. Christopher Columbus: his wife's version. New York: The permanent Press, 1994.

GUERRA, L. Mujer y escritura: fundamentos teóricos de la crítica feminista. México: Universidad Nacional Autónoma de México, 2007.

FERNÁNDEZ ÁLVAREZ, M. Casadas, monjas, rameras, y brujas: La olvidada historia de la mujer española en el renacimiento. Madrid: Espasa Calpe, 2002.

FERNÁNDEZ PRIETO, C. Historia y novela: poética de la novela histórica. 2. ed. Barañáin: EUNSA, 2003.

FLECK, G. F. O romance histórico contemporâneo de mediação: entre a tradição e o desconstrucionismo - releituras críticas da história pela ficção. Curitiba: CRV, 2017.

HUTCHEON, L. Poética dos pós-modernismo. Trad. Ricardo Cruz. Rio de Janeiro: Imago, 1991.

MADARIAGA, S. de. Vida del muy magnífico Señor Cristóbal Colón. Buenos Aires: Editorial Sudamericana, 1947.

MANSILLA, E. Lucía Miranda (1860). (Ed. María Rosa Lojo). Madrid: Iberoamericana, 2007. 
MENENDÉZ PELAYO, M. Estudios sobre el teatro de Lope de Vega. In: GONZÁLEZ PALENCIA, A. (Dir.). Edición nacional de las obras completas de Menéndez Pelayo. Madrid: Consejo Superior de Investigaciones Científicas, 1949.

MIRANDA, Ana. Desmundo. São Paulo: Companhia das letras, 1996.

MUÑEZ PUELLES, V. Anacaona. Barcelona: Tusquets, 1981.

NAVARRO SALAZAR, M. T. Mujer e identidad en la narrativa histórica femenina. Reflexiones sobre la novela histórica. José Jurado Morales. Cádiz: Servicio Publicaciones UCA, 2006.

PASTOR, B. Discurso narrativo de la conquista de América. Havana: Casa de las Américas, 1983.

PINILLA, L. D. B. Anacaona y las tormentas. Fondo de cultura económico: México, 1994.

PIQUERAS, P. Colón a los ojos de Beatriz. Barcelona: Ediciones Martínez Roca, 2000.

ROA BASTOS, A. Vigilia del Almirante. Asunción: RP Ediciones, 1992.

SCHMIDT, R. T. X Seminário Internacional de História da Literatura. A história da literatura tem gênero? Notas do tempo (in)acabado de um projeto. 2013. Disponível em: https://editora.pucrs.br/edipucrs/acessolivre/Ebooks//Web/x-sihl/media/mesa-7.pdf. Acesso em: 3 jun. 2021.

WASSERMANN, J. Cristóbal Colón: el Quijote del Océano. Trad. Eugenio Asensio. Madrid: Ulises, 1930. 